\section{Strain differences in memory and incentive as a function of external stimulation*}

\author{
MERRILL F. ELIAS, Duke University Medical Center, Durham, N.C. 27706 \\ and
}

SCOTT J. SIMMERMAN, Allegheny College, Meadville, Pa. 16335

Inbred mouse strains $\mathrm{DBA} / 2 \mathrm{~J}$ and $\mathrm{C} 57 \mathrm{BL} / 6 \mathrm{~J}$ were subjected to either air blast or control handling immediately after each of 30 spatial discrimination trials given 22 to $26 \mathrm{~h}$ apart. Errors were more frequent and swimming times were longer for the air-blast group of the C57BL/6J strain. Data were interpreted in terms of interference with memory consolidation and incentive to respond by means of aversive external stimulation.
The consolidation theory of memory states that the memory trace must be maintained for some period of time in order to be fixed in long-term memory. This hypothesis has received support from studies of electroconvulsive shock (e.g., Madsen \& McGaugh, 1961), $\mathrm{CO}_{2}$ (Quinton, 1966), anesthesia (e.g., Elias \& Simmerman, 1970; Pearlman, Sharpless, \& Jarvik, 1961), and other treatments that appear to disrupt the memory trace prior to consolidation. Jacobs \& Sorenson (1969) have pointed out that these treatments differ from S's natural environment by acting directly on the central nervous system and by altering electrical and chemical activity of the brain. They demonstrated the usefulness to the investigation of memory processes of stimuli that do not cause unconsciousness, seizures, or gross electrochemical changes in the nervous system. Immersion of Swiss-Webster albino mice in hot $\left(48^{\circ} \mathrm{C}\right)$ or cold $\left(1^{\circ} \mathrm{C}\right)$ water for $10 \mathrm{sec}$ impaired retention of a passive avoidance habit when immersion occurred no later than 2 sec after a single acquisition trial. These data do not support Calhoun's (1966) hypothesis that external stimulation must be task specific, e.g., stimulation with light for a visual discrimination (Thompson, 1957; Thompson \& Bryant, 1955) in order to interfere with memory trace consolidation. The purpose of the present experiment was to extend knowledge concerning the range of stimuli that interfere with memory trace consolidation and to explore differences between inbred mouse strains $\mathrm{DBA} / 2 \mathrm{~J}$ and $\mathrm{C} 57 \mathrm{BL} / 6 \mathrm{~J}$ in response to stimulation designed to disrupt retention. It was hypothesized that a blast of air (air blast)

* This research was supported by The United Health Services of North Carolina and by Research Training Grant 5T01HD00164 from the National Institute of Child Health and Human Development. detail by Waller, Waller, \& Brewster (1960) was a sheet-metal T maze with rounded arms and no top or bottom. It was immersed to a depth of $15-20 \mathrm{~cm}$ in a tank of water $\left(24^{\circ} \pm 1^{\circ} \mathrm{C}\right)$. A trial consisted of swimming from the start point of the maze to a ladder located at the correct arm. The correct arm was defined for each $\mathrm{S}$ as that chosen on less than half of 20 habituation trials, in which $S$ could escape from either arm. During testing, $\mathrm{S}$ was permitted to find the correct arm and escape if an incorrect turn was made. The top-bottom orientation of the maze was reversed between trials to control possible olfactory and visual cues. A 2 by 2 by 3 factorial design was used. Half the $S$ s in each strain received air blast and half received control handling immediately after each daily trial. Each $\mathrm{S}$ in the air-blast group was placed in an $18 \times 18 \times 18 \mathrm{~cm}$ Plexiglas box, and compressed air (approximately 25 psi) was trained on it from a height of $12 \mathrm{~cm}$ for $15 \mathrm{sec}$. The control-handling group was placed in an identical box for the same length of time. The 30 discrimination trials, presented 22 to $26 \mathrm{~h}$ apart, were arranged in three blocks of 10 trials each for purposes of analyses of variance. The two performance measures, percent errors and swimming time from start point until $S$ entered either the correct or the incorrect arm of the maze, met $\mathrm{DBA} / 2 \mathrm{~J}$. The apparatus, described in

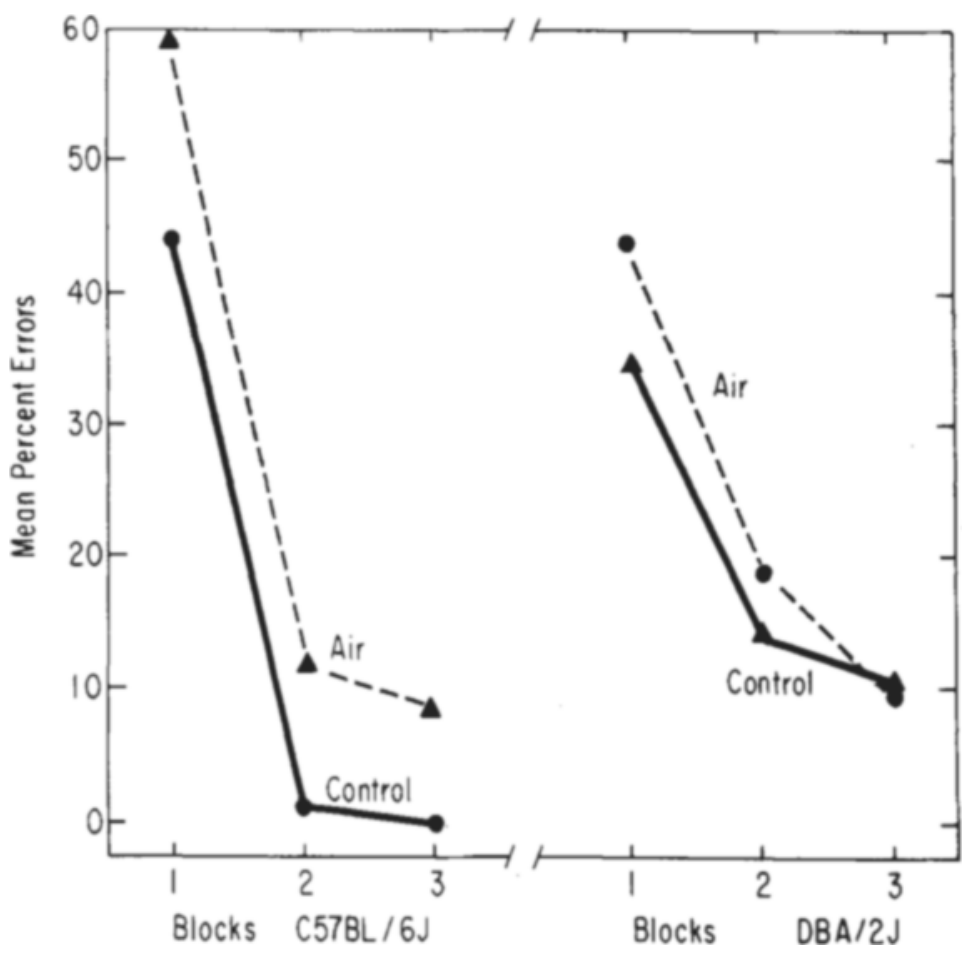

Fig. 1. Mean percent errors for blocks of 10 trials each for all experimental conditions. 

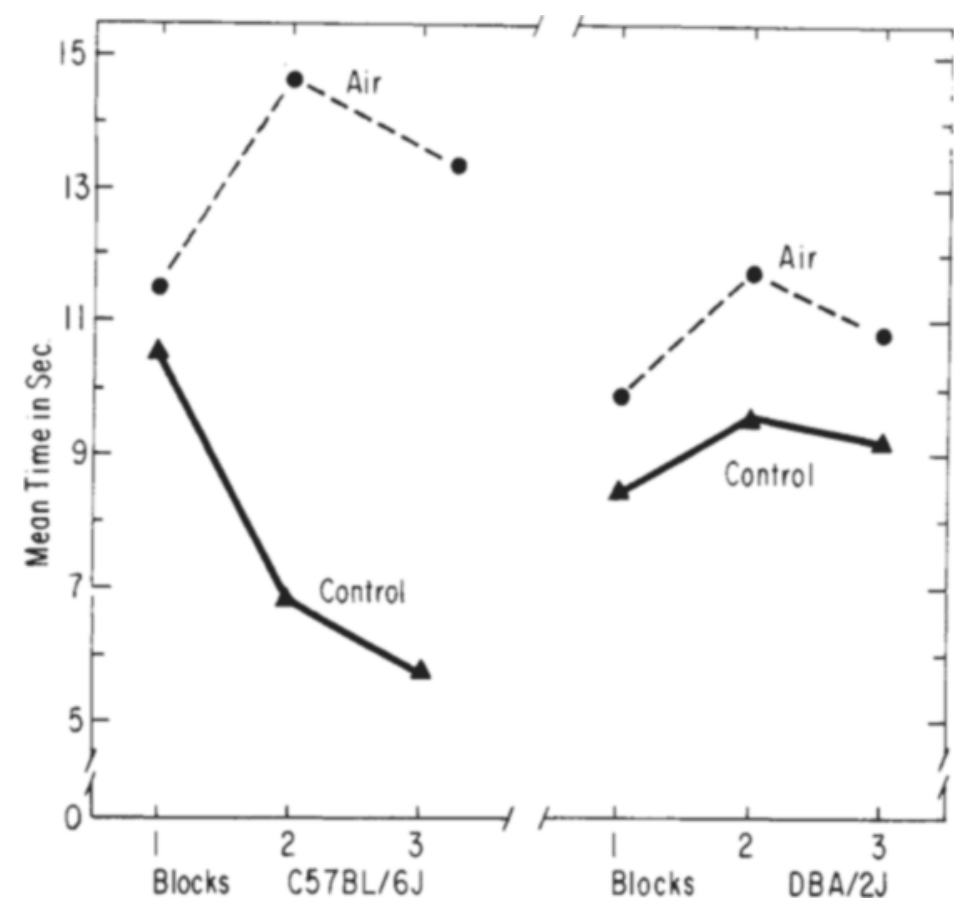

Fig. 2. Mean swimming times for blocks of 10 trials each for all experimental conditions.

assumptions underlying analyses of variance.

\section{RESULTS}

Figure 1 shows mean percent errors for the three blocks of trials. Differences between strains were not significant $(\mathrm{F}=.48, \quad \mathrm{~d} f=1 / 92$, $\mathrm{p}>.05$ ) when errors were averaged over treatments and blocks. However, Ss that received air blast made significantly $(F=8.42, \quad d f=1 / 92$, $\mathrm{p}<.01)$ more errors than Ss that received control handling. There was also a significant Strain by Treatment interaction $(\mathrm{F}=4.60, \quad \mathrm{df}=1.92$, $\mathrm{p}<.05$ ), and tests of simple main effects (Winer, 1962 , p. 320 ) revealed a significantly higher $(\mathrm{F}=12.77$, df $=1 / 92, \quad p<.01$ ) percentage of errors for the air-blast group than for the control-handling group for the C57BL/6J strain but not for the $\mathrm{DBA} / 2 \mathrm{~J}$ strain $(\mathrm{F}=.28, \quad \mathrm{df}=1 / 92$, $p>.05$ ). It may be noted in Fig. 1 that although the air-blast group of the C57BL/6J strain made more errors than the control-handling group over all blocks of trials, the rate of improvement was approximately the same for both groups. There was a significant Strain by Blocks interaction $(\mathrm{F}=21.83, \mathrm{df}=2 / 184, \mathrm{p}<.01)$ and it may be seen in Fig. 1 that the C57BL/6J strain showed a wider range of scores and a greater amount of improvement from Block 1 to Block 3 .

Figure 2 shows swimming times under all conditions. Averaging times over strains and blocks, Ss that
DISCLSSION

The Strain by Treatment interaction for both the error and time measure suggests that the effect of aversive stimulation on retention and incentive may be expected to vary as a function of genetic background. Assuming that decreased swimming time reflects increased escape incentive (Waller et al, 1960), it appears that air blast had a more pronounced effect on incentive for the $\mathrm{C} 57 \mathrm{BL} / 6 \mathrm{~J}$ mice. In contrast to the relatively parallel time curves for the air-blast and control-handling groups of the DBA/2J strain, the air-blast and control-handling groups of the C57BL/6J strain showed widely divergent times on Blocks 2 and 3 with the air-blast group showing significantly slower times. The air-blast group also showed a significantly higher percentage of errors than the control-handling group for the C57BL/6J strain, but not for the DBA/2J strain. However, the error curves showed a negative and parallel trend for the air-blast and control-handling groups, while the time curves showed increasingly divergent times for these two groups. The fact that the curves for escape times did not show the same trends as those for errors suggests that decreased incentive to escape does not explain the increased percentage of errors for the air-blast group. An alternative interpretation appears to be that a disruptive effect of aversive stimulation on memory was seen as early as the first block of trials and progressed in equal increments across the remaining blocks. A more difficult task, such as visual discrimination learning, might have revealed differences between air-blast and control-handling groups in the rate of error elimination as well as in the presently observed differences in overall percentage of errors.

The fact that error and time scores were increased by aversive stimulation suggests that the deleterious effects on performance of posttrial etherization (e.g., Elias \& Simmerman, 1970; Pearlman et al, 1961) may be related, not only to electrochemical changes accompanying ether induction, but to aversive side effects and consequent behavior which accompanies ether induction, e.g., jumping, running, and struggling. The fact that incentive to escape was decreased by air blast suggests that increased shock avoidance latencies following aversive stimulation (e.g., Jacobs \& Sorenson, 1969) may reflect decreased incentive to respond rather than defective memory for the appropriate response.

These data do not support Calhoun's (1966) suggestion that external stimulation must be task 
specific in order to disrupt memory consolidation. Calhoun's failure to find retarded spatial discrimination learning in mice exposed to a buzzer, light, or rocker may have been due to the fact that these stimuli were presented after blocks of trials rather than after single trials. It is possible that consolidation of the memory traces from earlier trials in the block had taken place prior to the presentation of the aversive stimuli after the last trial. It is also possible that Calhoun's C57BL/crgl strain of mice was less responsive to aversive stimulation than the mice of the present experiment. Certainly, data of the present experiment indicate that strain differences must be considered when conflicting data are compared.

\section{REFERENCES}

CALHOUN, $W$. $H$. Effect of level of external stimulation on rate of learning and interaction of this effect with strychnine treatment in mice. Psychological Reports, 1966, 18 , 715-722.

ELIAS, M. F., \& SIMMERMAN, S. J, Proactive and retroactive effects of diethyl ether on spatial discrimination learning for two inbred mouse strains.
Paper presented at the Eastern Psychological Association, Atlantic City, N.J., April 1970.

JACOBS, B. L., \& SORENSON, C. A. Memory disruption in mice by brief posttrial immersion in hot or cold water. Journal of Comparative \& Physiological Psychology, 1969,68, 239-244.

MADSEN, M. C.. \& McGAUGH, J. L. The effect of ECS on one-trial avoidance learning. Journal of Comparative \& Physiological Psychology, 1961, 54, 522-523.

PEARLMAN, C. A., SHARPLESS, S. K., \& JARVIK, M. E. Retrograde amnesia produced by anesthetic and convulsant agents. Journal of Comparative \& Physiological Psychology, 1961, 54, 109-112.

QUINTON, E. E. Retrograde amnesia induced by carbon dioxide inhalation. Psychonomic Science, 1966, 5, 417-418.

THOMPSON, R. Retroactive effect of interpolated visual stimulation. Psychological Reports, 1957, 3, 183-188.

THOMPSON, R., \& BRYANT, J. H. Memory as affected by activity of the relevant receptor. Psychological Reports, $1955,1,393-400$.

WALLER, M. B., WALLER, P. F., \& BREWSTER, L. A. A water maze for use in studies of drive and learning. Psychological Reports, 1960, 10, 147-150.

WINER, B. J. Statistical principles in experimental design. New York: MeGraw-Hill, 1962.

\title{
Visual probability learning in the rat*
}

\author{
M. E. BITTERMAN \\ University of South Florida, Tampa, Fla. 33620
}

The mean asymptotic choice ratios of three groups of rats trained in 100:0, 70:30, and 50:50 visual problems corresponded closely to the reinforcement ratios. A fourth group of rats, which was shifted to 70:30 after some 100:0 training, continued for many trials to show a preference for the $70 \%$ alternative which substantially exceeded that of the 70:30 group. Examination of individual performances revealed a variety of systematic tendencies quite different from the random probability matching found in submammalian forms.

Experiments on probability learning
in mammals sometimes show
correspondences between choice ratios
and reinforcement ratios which are
reminiscent of the probability
matching found in fishes and other
submammalians (Behrend \& Bitterman, 1966 ; Bullock \& Bitterman, 1962; Kirk \& Bitterman, 1965; Longo, 1964). Although the resemblance turns out upon analysis to be entirely superficial-the correspondence is an artifact of averaging in some cases and of systematic tendencies such as reward following and negative recency in others (Longo \& Beideman, 1966; Poland \& Warren, 1968; Weizman \& Guthrie, 1968; Wilson, Oscar, \&

* This research was supported by Grant MH 17736 from the Public Health Service. The data were collected by Diana Wilkins.
Bitterman, 1964)-it continues to be taken as evidence for the view that all of the data can be understood in terms of a common set of principles. According to Mackintosh (1969), for example, experiments on probability learning in rats, birds, and fishes show only quantitative differences in behavior. The tendency to maximize, he claims, is greater in rats than in birds and greater in birds than in fishes, which can be explained in terms of a theory like Sutherland's (1964) on the assumption that failure to maximize is due to the weakening of attention to relevant cues by inconsistent reinforcement and that the ability to maintain attention in the face of inconsistent reinforcement is greater in rats than in birds and greater in birds than in fishes. I report here some further data on visual probability learning in rats which bear on the correctness of this view.

\section{METHOD}

The Ss were 38 experimentally naive white rats about 90 days old when they were obtained from a local dealer. After several weeks of adaptation to the laboratory, the animals were placed on a 24 -h feeding schedule and gradually reduced to $85 \%$ of free-feeding weight.

The apparatus was a modified two-window Lashley stand. Narrow elevated pathways (2.25 in. wide) branched out to the windows from a small starting platform 9 in. away. The windows were $5.5 \mathrm{in}$. square and 3.5 in. apart. The response of $\mathrm{S}$ was to run from the starting platform to one of the windows and to push against the stimulus card which it displayed. The goalbox behind the correct card contained a food dish with four 45-mg Noyes pellets, while the goalbox behind the incorrect card was empty. Except for the cards, which were black and white, the entire apparatus was painted gray.

After extensive pretraining, the Ss were divided into four groups of approximately equal size which were matched for adjustment to the experimental situation. In the experiment proper, each animal had 10 massed trials per day for 50 days. On each trial, there was a white card in one window and a black card in the other, the positions of the two cards being varied from trial to trial in accordance with Gellermann orders. One group of $10 \mathrm{Ss}$ was trained on a 100:0 schedule, half with white positive and half with black positive. Another group of $8 \mathrm{Ss}$ was trained on the 100:0 schedule (half with black positive and half with white) for 16 days, and then it was shifted to a 70:30 schedule (the previous 100\% brightness now being reinforced on only $70 \%$ of trials). A group of $9 \mathrm{Ss}$ was trained from the beginning on the 70:30 schedule (half with black as the $70 \%$ brightness and half with white). A group of 11 Ss was trained throughout on a 50:50 schedule. The 70:30 schedule was random, with the restriction that there be at least one minority reinforcement in each block of five trials and that the $70: 30$ ratio obtain in each block of 10 trials. The 50:50 schedule was random, with the restriction that each brightness be rewarded at least once in each block of five trials and that the 50:50 ratio obtain in each block of 10 trials. A guidance procedure was used throughout; after an incorrect response, the animal was permitted to remain in the empty goalbox for $5 \mathrm{sec}$ and then returned to the starting platform, from which point it was guided manually to the correct card. Each trial thus ended with reinforcement. 